NASA Technical Memorandum 102534

\title{
Coplanar Waveguide Discontinuities for P-I-N Diode Switches and Filter Applications
}

N.I. Dib and P.B. Katehi

University of Michigan

Ann Arbor, Michigan

G.E. Ponchak

Lewis Research Center

Cleveland, Ohio

R.N. Simons

Case Western Reserve University

Cleveland, Ohio

Prepared for the

1990 IEEE MTT-S International Microwave Symposium

Dallas, Texas, May 8-10, 1990

\section{N/SN}

(NASA-TM-102534) CTPLANAP WAVEGUIDE

DISCONTINUITIFS FDR P-I-N OIODE SWITCHES ANO

FILTER APPLICATIONS (NASA) $10 \mathrm{P}$ CSCL O9C

$N 90-21278$ 


\title{
COPLANAR WAVEGUIDE DISCONTINUITIES FOR P-I-N DIODE SWITCHES
}

\author{
AND FILTER APPLICATIONS \\ N.I. Dib and P.B. Katehi \\ Radiation Laboratory \\ University of Michigan \\ Ann Arbor, Michigan 48109 \\ G.E. Ponchak \\ National Aeronautics and Space Administration \\ Lewis Research Center \\ Cleveland, Ohio 44135 \\ R.N. Simons* \\ Case Western Reserve University \\ Cleveland, Ohio 44106
}

\section{SUMMARY}

A full wave space domain integral equation (SDIE) analysis of coplanar waveguide (CPW) two port discontinuities is presented. An experimental setup to measure the S-parameters of such discontinuities is described. Experimental and theoretical results for CPW realizations of pass-band and stop-band filters are presented. The S-parameters of such structures are plotted in the frequency range 5 to $25 \mathrm{GHz}$.

\section{INTRODUCTION}

The coplanar waveguide (CPW) was introduced for the first time in 1969 by C.P. Wen (ref. 1) as an appropriate transmission line for nonreciprocal gyromagnetic device applications. Recently, with the push to high frequencles and monolithic technology, CPW's have experienced a growing demand due to the ir appealing properties (refs. 2 and 3 ). However, the extent of applications of CPW circuits is limited due to the unavallability of circuit element models which can be incorporated into CAD programs. Houdart (ref. 2) proposed several configurations using the coplanar line technique in order to realize basic types of elements requifed in MIC's.

Microwave switches are circuit elements widely used in phase shifters and radiometers. A CPW Switchable attenuating medium propagation, SAMP, switch has been demonstrated by fleming et al. (ref. 4). This device is useful for GaAs MMIC circuits but it is not easily incorporated into MIC's on passive substrates such as alumina or duroid. P-i-n diodes are good microwave switches since the impedance of the diode can be changed from a very high value to nearly zero in a short time. Recently, CPW $p-i-n$ diode switches were proposed and fabricated (ref. 6). Figure 1 shows a switch where a diade is mounted across the open end of a quarter wavelength stub which is in series with the

*NASA Resident Research Associate at Lewis Research Center; present address: Sverdrup Technology, Inc., NASA Lewis Research Center Group, Cleveland, Ohio 44135. 
center strip conductor of the CPW. The two states of the switch, ON and OFF, can be realized separately by appropriate CPN discontinuities which in turn can be used to bulid pass-band and stop-band filters respectively (refs. 2,7 and 8 ).

In this paper, the space domain integral equation (SDIE) method, presented in reference 5 is extended to analyze the $S$-parameters of the CPW realization of the above switches, figure 2. Experimental results are compared to theoretical data and a good agreement is achieved. The experimental setup, measurement technique and the sources of error are described. As a next step, the study of the switches will be completed by including the diode as a lumped element in the method of moments solution. Thus, the ON and OFF states of the switch will be predicted from the same structure without having to go to different CPW discontinuities for realization of these states.

\section{THEORY}

The coplanar line under consideration is shown in figure 3 . The measurements were performed using an open CPW structure. However, in the theoretical analysis the $\mathrm{CPW}$ is assumed to be inside a rectangular cavity of perfectly conducting walls as opposed to experiments where open structures were measured. The cavity dimensions were chosen such that the CPW fundamental mode is not affected by higher order cavity resonances.

The original boundary problem is split into two simpler ones by introducing an equivalent magretic current $\bar{M}_{5}$, on the slot aperture. This surface magnetic current radiates an electromagnetic field in the two waveguide regions (above and below the slot) so that the continuity of the electric field on the surface of the slots is satisfied. The remaining boundary condition to be applied is the continuity of the tangential magnetic field on the surface of the slot apertures which leads to the following integral equation

$$
\hat{n} \times \int_{s} \int\left[\bar{G}_{1}^{h}-\bar{G}_{2}^{h}\right] \cdot \bar{M}_{s}\left(\bar{r}^{\prime}\right) d s^{\prime}=J_{s} \text {, }
$$

where $\bar{G}_{1,2}^{h}$ are the magnetic dyadic Green's functions in the two waveguide regions (ref. 5) and $J_{S}$ denotes the ideal current source feeding the $C P W$, (gap generator model).

The integral equation (1) is solved using the method of moments where the unknown magnetic current is expanded in terms of rooftop basis functions.

Then, Galerkin's method is applied to reduce the above equation to a linear system of equations

$$
\left(\begin{array}{cc}
Y_{y y} & Y_{z y} \\
Y_{y z} & Y_{z z}
\end{array}\right)\left(\begin{array}{c}
V_{y} \\
V_{z}
\end{array}\right)=\left(\begin{array}{c}
I_{y} \\
I_{z}
\end{array}\right)
$$

where $Y_{i j}(i=y, z ; j=y, z)$ represent blocks of the admittance matrix, - (ref. 5) $\nabla_{j}$ is the vector of unknown $y$ and $z$ magnetic current amplitudes, and $I_{j}$ is the excitation vector which is identically zero everywhere except at the position of the sources. Finally, the equivalent magnetic current distribution and consequently the electric field in the slots are obtained by matrix inversion. 
Away from the discontinuity, the slots fields form standing waves of the fundamental CPW propagating mode. Using the derived electric field, an ideal transmission line method as described in reference 9 is applied to determine the scattering parameters of the two port discontinuity.

\section{EXPERIMENT}

The circuits were fabricated using a liftoff procedure. A $2.8 \mu \mathrm{m}$ gold layer was electron beam evaporated onto a $25 \mathrm{mil}$ thick polished alumina substrate $\left(\epsilon_{r}=9.9\right)$. The alumina substrate was placed on a $125 \mathrm{mil}$ thick 5880 RT/Duroid $\left(\epsilon_{r}=2.2\right)$ substrate with copper cladding on one side to serve as the bottom ground plane.

The RF measurements were performed using HP8510ANA and a probe station with design techniques $D C-26 \mathrm{GHz}$ probes. In order to measure the circuit elements, an LRL calibration (ref. 10) was performed to remove the effects of the system to the reference plane PP' ( $f i g .4$ ) using E-Esof ANACAT software (ref. 11). The calibration standards shown in figure 5 were fabricated on the same substrate as the circuits.

\section{RESULTS AND DISCUSSION}

For the solution of reference 2 , most of the computation effort is spent on the evaluation of the elements of the admittance submatrices. These elements involve double summations in their computation which are inherently slowly convergent. Details on the numerical evaluation of these summations may be found in reference 2. Extensive numerical experiments were performed on the convergence of the S-parameters with respect to the above summations and the number of basis functions used in the expansion of the slot fleld. Both were chosen such that at least 2 percent accuracy is achieved.

Figure 6 shows the scattering parameters for the short circuit CPW stub ( $S C-C P W$ stub) of length $500 \mu \mathrm{m}$. It can be seen that the agreement between the theoretical and experimental results is very good. The differences can be due to conduction losses and radiation losses since an open structure was used in the measurements. Figure 7 shows the scattering parameters for the SC-CPW stub of length $1500 \mu \mathrm{m}$. From these results it can be observed that a resonance occurs when the stub length is slightly less than a quarter wavelength ( $\lambda_{g} \sim$ $6.14 \mathrm{~mm}$ at $f=21 \mathrm{GHz}$ ). This is due to the inductive reactance which exists at the end of the stub as a result of the end effect. A stop-band filter can be realized by cascading several SC-CPW stubs in series.

Figures 8 and 9 show the scattering parameters for the open circuit $\mathrm{CPW}$ stub (OC-CPW stub) of length $500 \mu \mathrm{m}$ and $1500 \mu \mathrm{m}$ respectively. It can be seen from figure 9 that $S_{11}\left(S_{12}\right.$ ) has its minimum (maximum) value at $f=19 \mathrm{GHz}$ at which $\lambda_{g} / 4 \sim 1.7 \mathrm{~mm}$. This is due to the capacitive end effect of the stub. Such structures operate as pass-band filters. The agreement between the theoretical and experimental results is very good.

The errors associated with the measured data are nonrepeatability in probe placement and pressure and circuit fabrication tolerances. The circuit dimension variations across the $2 \mathrm{in}$. by $2 \mathrm{in}$. alumina substrate were negligible as 
was the variation in the gold thickness. The circuit dimensions varied by, at most, 1 percent compared to the designed dimensions. The probe placement was repeatable to $5 \mu \mathrm{m}$. The probe pressure created the largest uncertainty in the measurements since it changed the contact between the alumina and the duroid substrates. One further consideration is that the spacing between circuits on the substrate was approximately $(S+2 W) / 2$ which resulted in a finite size ground planes.

\section{CONCLUSIONS}

The space domain integral equation method solved by the method of moments (Galerkin's technique) in conjunction with simple transmission line theory was applied to analyze CPW realizations of pass-band and stop-band filters. An experimental setup to measure the S-parameters of those structures has been described and the various sources of error were discussed. The agreement between the theoretical data and the experimental measurements was very good, thus, the validity of both results is verified.

\section{ACKNOWLEDGMENT}

The theoretical part of this paper was supported by the National Science Foundation under contract ECS-8657951.

\section{REFERENCES}

1. C.P. Wen, "Coplanar Waveguide: A Surface Strip Transmission Line Sultable for Nonreciprocal Gyromagnetic Device Applications," IEEE Trans. Microwave Theory Tech., vol. MTT-17, pp. 1087-1090, 1969.

2. M. Houdard, "Coplanar Lines: Application to Broadband Microwave Integrated Circuits," 6th European Microwave Conference, Microwave Exhibitions and Publishers, England, pp. 49-53, 1976.

3. K.C. Gupta, R. Garge, and I.J. Bahl, Microstrip Lines and Slotlines, Dedham, MA: Artech House, 1979.

4. P.L. Fleming, T. Smith, H.E. Carlson, and W.A. Cox, "GaAs SAMP Device for Ku-Band Switching," IEEE Trans. Microwave Theory Techniques, vol. MTT-27, pp. 1032-1035, 1979 .

5. N.I. Dib and P.B. Katehi, "Modeling of Shielded CPW Discontinuities Using the Space Domain Integral Equation Method (SDIE)," submitted to the Journal of Electromagnetic Waves and Applications, Special Issue on Electromagnet ism and Semiconductors.

6. G.E. Ponchack and R.N. Simons, "Channelized Coplanar Waveguide PIN-Diode Switches," 19th European Microwave Symposium Digest, Microwave Exhibitions and Publishers, England, pp. 489-494, 1989 (Also, NASA TM-102289).

7. R.N. Bates, "Design of Microstrip Spur-Line Band-Stop Filters," IEE J. Microwave, Optics Acoustics, vol. 1, pp. 209-214, 1977. 
8. D.F. Williams and S. Schwarz, "Design and Performance of Coplanar Wavegulde Bandpass Filters," IEEE Trans. Microwave Theory Techniques. vol. MTT-31, pp. 558-566, 1983 .

9. P.B. Katehi, "A Generalized Method for the Evaluation of Mutual Coupling in Microstrip Arrays," IEEE Trans. Antennas Propagat., vol. AP-35, pp. 125-133, 1987 .

10. P.R. Pantoja, M.J. Howes, J.R. Richardson, and R.D. Pollard, "Improved Calibration and Measurement of the Scattering Parameters of Microwave Integrated Circuits," IEEE Trans. Microwave Theory Techniques, vol. MTT-37, pp. 1675-1680, 1989.

11. Anacat User's Manual, E-Esof Inc.

12. L.P. Dunleavy and P.B. Katehi, "A Generalized Method for Analyzing Shielded Thin Microstrip Discontinutties," IEEE Trans. Microwave Theory Techniques, vol. MTT-36, pp. 1758-1766, 1988.
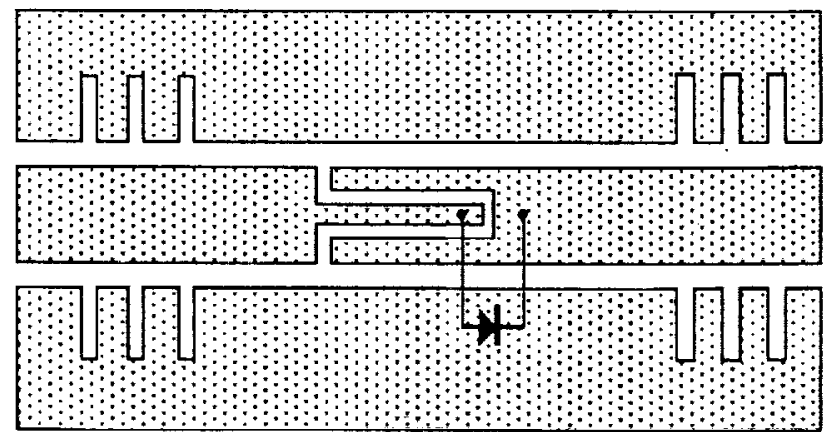

FIGURE 1. - SCHEMATIC DIAGRAM OF CPW P-I-N DIODE SWITCHED SERIESSTUB SWITCH. 

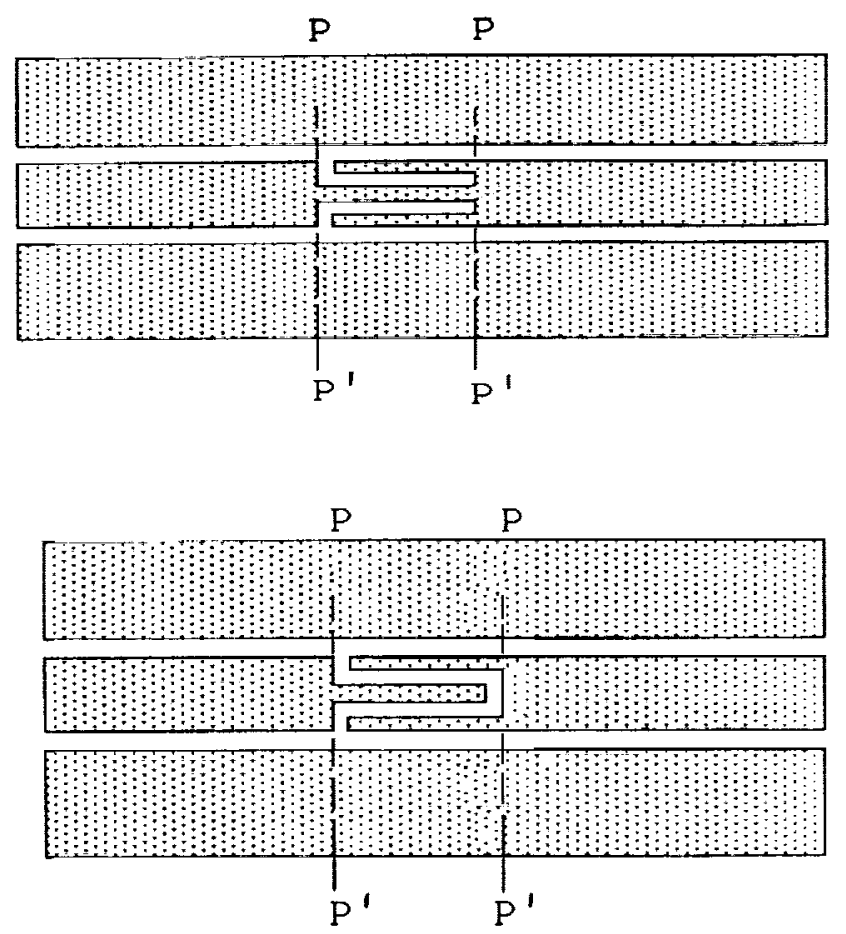

FIGURE 2, - CPW REALIZATIONS OF STOP-BAND AND BAND-PASS FILTERS.

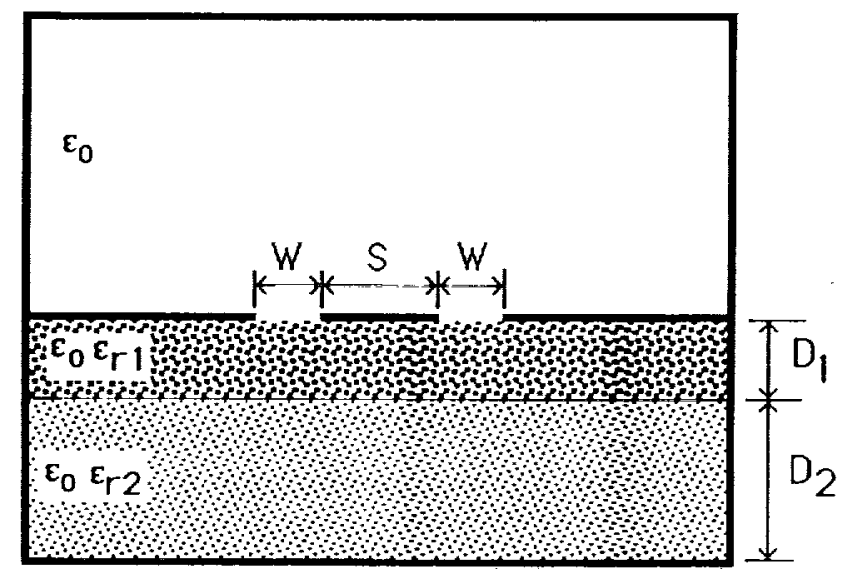

FIGURE 3. - COPLANAR WAVEGUIDE INSIDE A CAVITY.

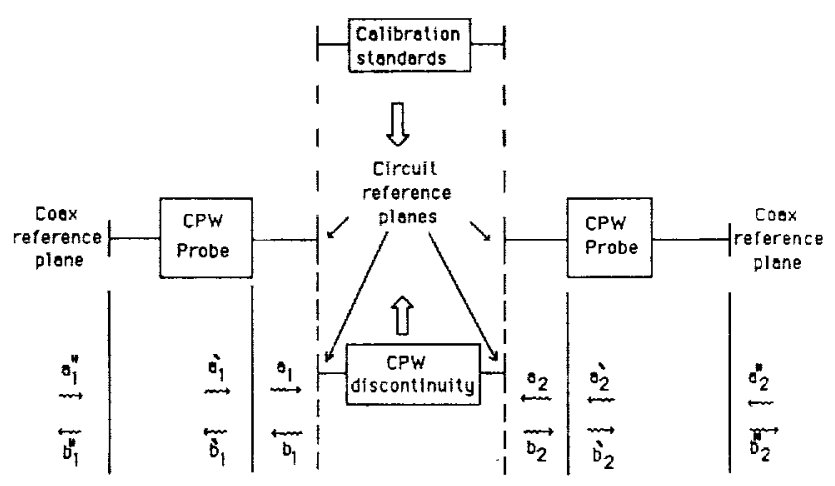

FIGURE 4. - BASIC CONCEPT OF DE-EMBEDDING. 


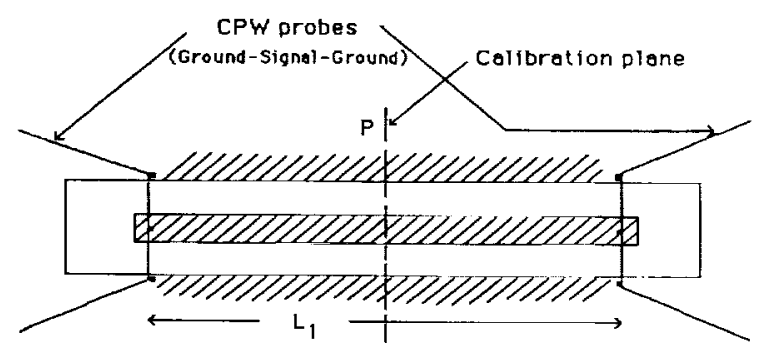

(a) DELAY OF LENGTH $L_{1}$.

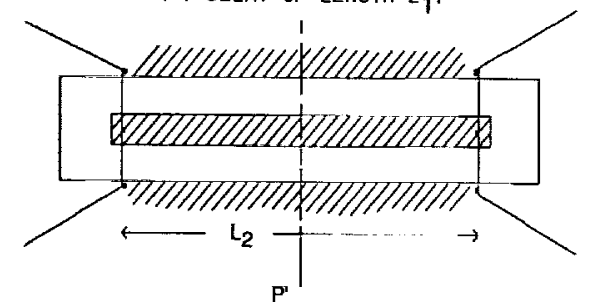

(b) DELAY OF LENGTH $L_{2}$.

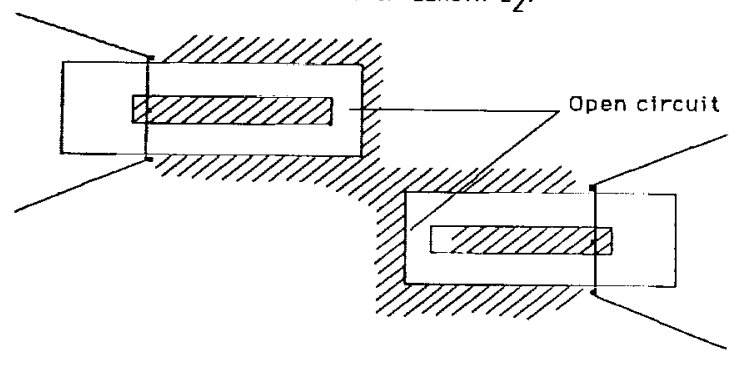

(c) REFLECTION OF ARBITRARY MAGNITUDE.

FIGURE 5. - CPW STANDARDS FOR LRL CALIBRATION.
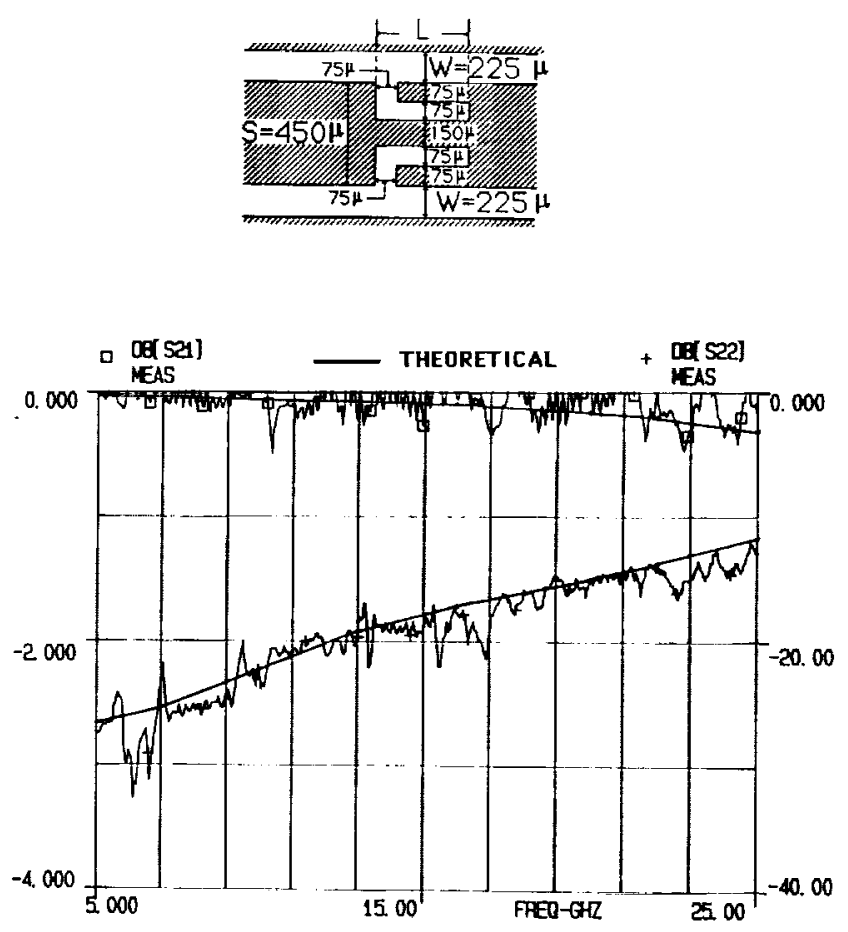

FIGURE 6. - S-PARAMETERS FOR SC-CPW STUB WITH $L=500 \mu \mathrm{m}$. $D_{1}=25 \mathrm{MIL}, D_{2}=125 \mathrm{MIL}, \varepsilon_{\mathrm{r} 1}=9.9, \varepsilon_{\mathrm{r} 2}=2.2$.

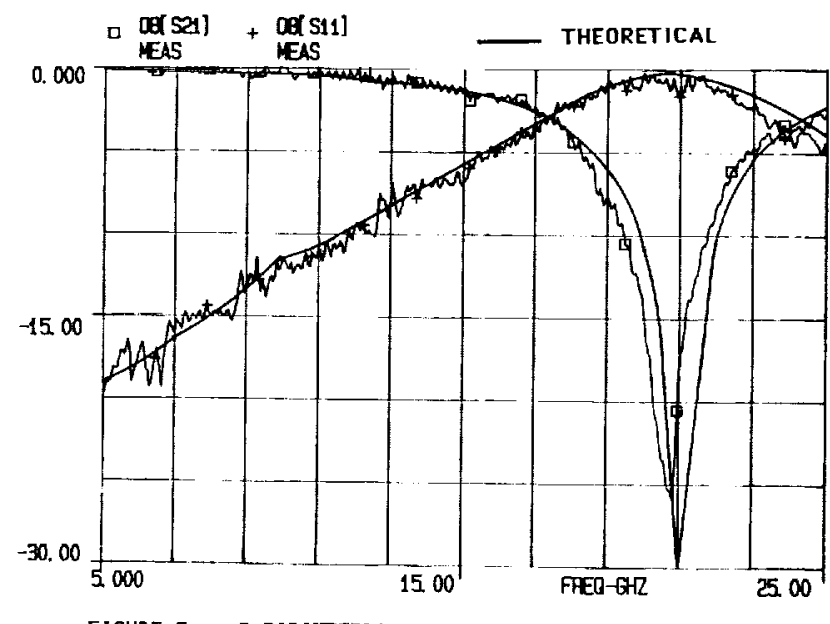

FIGURE 7. - S-PARAMETERS FOR SC-CPW STUB WITH L $=1500 \mu \mathrm{m}$. OTHER DIMENSIONS ARE THE SAME AS IN FIG, 6. 

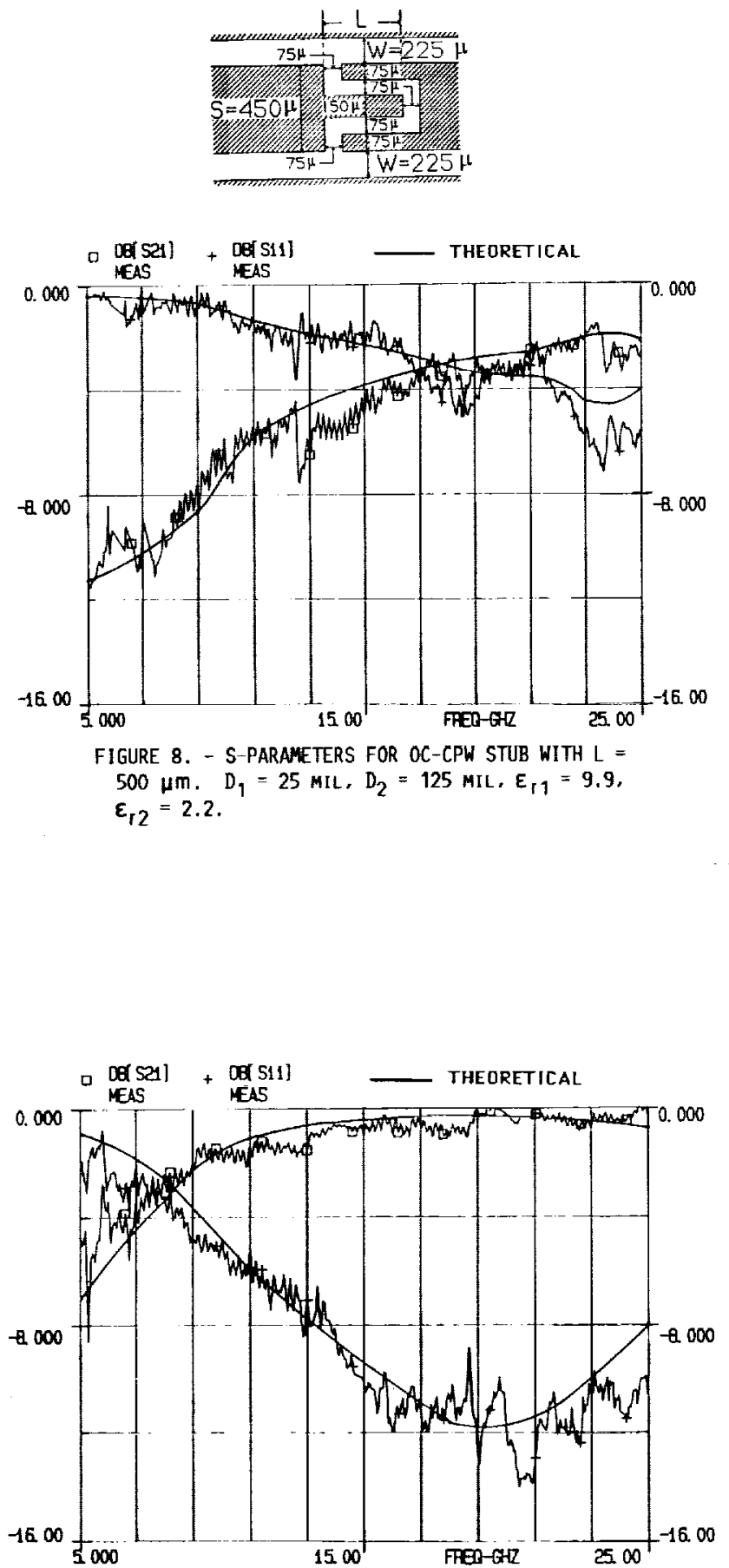

FIGURE 9. - S-PARARETERS FOR OC-CPN STUB WITH $L=$ $1500 \mu \mathrm{m}$, OTHER DIMENSIONS ARE THE SAME AS IN FIG. 8 . 


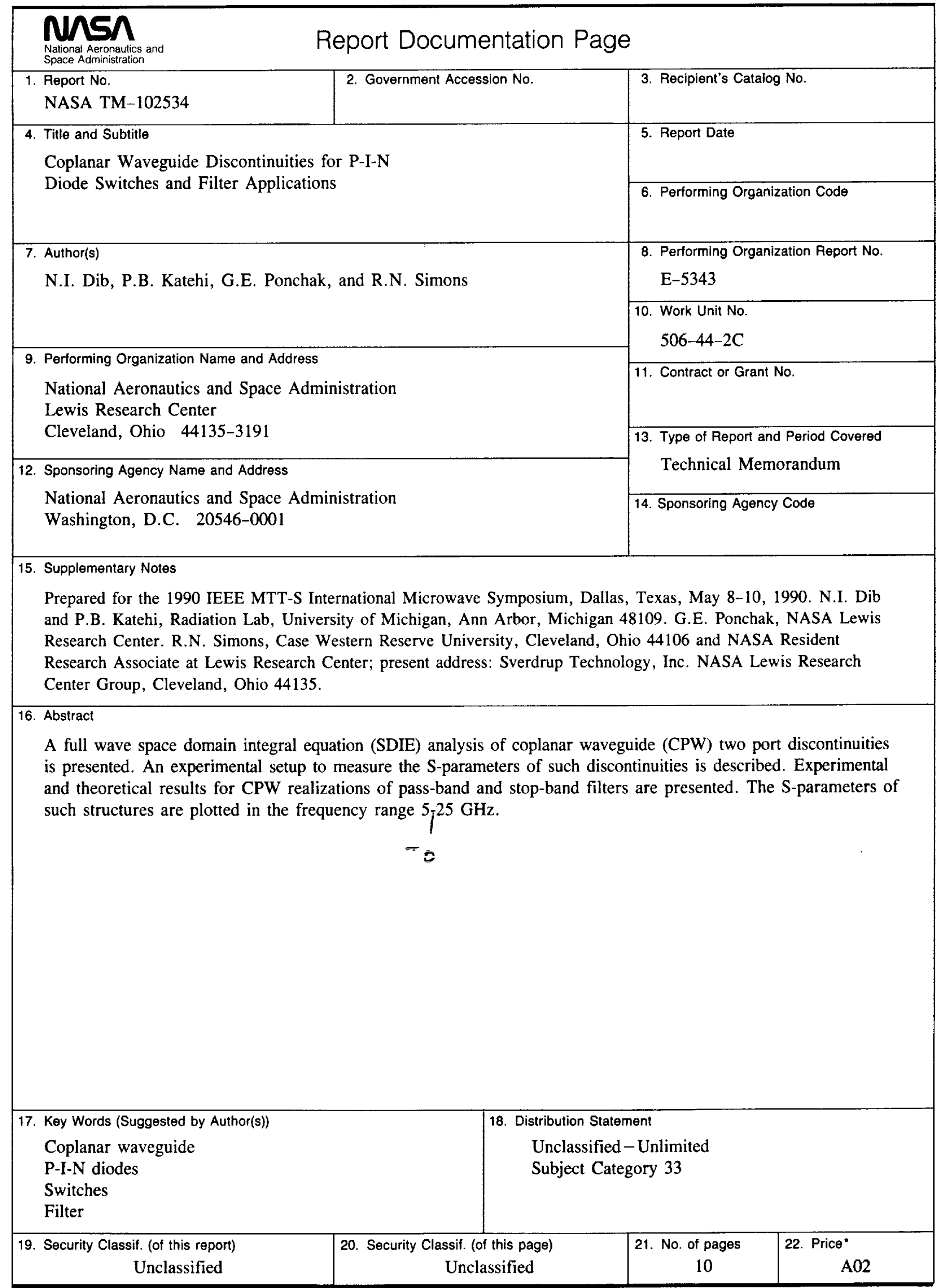


